\title{
Cardiopulmonary exercise testing and pulmonary function testing for predicting the severity of CTEPH
}

Hanqing Zhu ${ }^{1 \dagger}$, Xingxing Sun ${ }^{1 \dagger}$, Yuan Cao ${ }^{1}$, Bigyan Pudasaini ${ }^{2}$, Wenlan Yang ${ }^{1}$, Jinming Liu ${ }^{1}$ and Jian Guo ${ }^{1 *}$

\begin{abstract}
Background: Cardiopulmonary exercise testing (CPET) and pulmonary function testing (PFT) are noninvasive methods to evaluate the respiratory and circulatory systems. This research aims to evaluate and monitor chronic thromboembolic pulmonary hypertension (CTEPH) noninvasively and effectively by these two methods. Moreover, the research assesses the predictive value of CPET and PFT parameters for severe CTEPH.

Methods: We used data from 86 patients with CTEPH (55 for test set, and 31 for validation set) at the Shanghai Pulmonary Hospital Affiliated to Tongji University. The clinical, PFT and CPET data of CTEPH patients of different severity classified according to pulmonary artery pressure (PAP) $(\mathrm{mm} \mathrm{Hg})$ were collected and compared. Logistic regression analysis was performed to appraise the predictive value of each PFT and CPET parameter for severe CTEPH. The performance of CPET parameters for predicting severe CTEPH was determined by receiver operating characteristic (ROC) curves and calibration curves.
\end{abstract}

Results: Data showed that minute ventilation at anaerobic threshold (VE @ AT) (L/min) and oxygen uptake at peak $\left(\mathrm{VO}_{2} @\right.$ peak) $(\mathrm{mL} / \mathrm{kg} / \mathrm{min})$ were independent predictors for severe CTEPH classified according to PAP $(\mathrm{mm} \mathrm{Hg})$. Additionally, the efficacy of VE @ AT (L/min) and VO $\mathrm{O}_{2}$ @ peak $(\mathrm{mL} / \mathrm{kg} / \mathrm{min})$ in identifying severe CTEPH was found to be moderate with the area under ROC curve (AUC) of 0.769 and 0.740 , respectively. Furthermore, the combination of VE @ AT ( $/ \mathrm{min}$ ) and $\mathrm{VO}_{2} @$ peak ( $\mathrm{mL} / \mathrm{kg} / \mathrm{min}$ ) had a moderate utility value in identifying severe CTEPH with the AUC of 0.843 .

Conclusion: Our research suggests that CPET and PFT can noninvasively and effectively evaluate, monitor and predict the severity of CTEPH.

Keywords: CPET, PFT, CTEPH

\section{Background}

Cardiopulmonary exercise testing (CPET) provides a unique and comprehensive evaluation of respiratory and circulatory systems by detecting the gas exchange and exercise load during exercise [1]. It is considered to be

\footnotetext{
*Correspondence: jianjian11121978@163.com

${ }^{\dagger}$ Hanqing Zhu and Xingxing Sun have contributed equally to this study

${ }^{1}$ Department of Pulmonary Function Test, Shanghai Pulmonary Hospital,

School of Medicine, Tongji University, Shanghai 200092, China

Full list of author information is available at the end of the article
}

a gold standard of noninvasive measure of cardiorespiratory fitness and exercise capacity [2]. CPET has been widely carried out in patients with pulmonary hypertension $(\mathrm{PH})$, heart failure (HF), chronic obstructive lung disease (COPD), asthma, etc. [3-5]. It has been reported to be of significance in disease diagnosis, therapeutic efficacy evaluation and prognostic assessment. However, the variety of parameters makes it difficult for clinicians to interpret CPET reports accurately. 
The pathological characteristics of CTEPH are organized thrombus and vascular remodeling, which can lead to right ventricular failure [6]. Pulmonary endarterectomy (PEA), balloon pulmonary angioplasty (BPA) and $\mathrm{PH}$-targeted medicine are the main therapies of CTEPH [6]. The diagnosis of CTEPH can be achieved by right heart catheterization (RHC), ventilation/perfusion scan (V/Q) and CT pulmonary angiography (CTPA) [7, 8].

Since CTEPH is a kind of progressive disease, it is imperative to evaluate the severity of the CTEPH patients appropriately for timely intervention. It has already been reported that CPET may be used to estimate the severity of $\mathrm{PH}$ [9]. Abnormalities noted during CPET were consistent, characteristic and correlated well with primary pulmonary hypertension (PPH) patients' NYHA class $[10,11]$. Stepping on these, we set this study to examine the CPET performance difference between patients with mild-moderate and severe CTEPH.

\section{Methods}

\section{Ethical approval}

The study protocol was reviewed and approved by the Ethics Committee of Shanghai Pulmonary Hospital. Written informed consent was obtained from each patient for inclusion into the study prior to the performance of any study-related procedures.

All methods including CPET, PFT, RHC and blood test were carried out in accordance with relevant guidelines and regulations.

\section{Patients}

This study retrospectively enrolled 86 inpatients with CTEPH who were referred to Shanghai Pulmonary Hospital from November 2015 to December 2019. All patients were definitely diagnosed by RHC. Patients with mean pulmonary artery pressure $(\mathrm{mPAP}) \geq 25(\mathrm{~mm} \mathrm{Hg})$ and pulmonary arterial wedge pressure $(\mathrm{PAWP}) \leq 15$ $(\mathrm{mm} \mathrm{Hg})$ were considered to be diagnosed with CTEPH. They also should had thromboembolic disease performance which can be detected by ventilation/perfusion scan or pulmonary angiogram. Patients were excluded from study if they had any evidence of the following: right-to-left cardiac shunt, coexisting lung diseases (identified clinically or on CT scan), FEV1/FVC\% $<65 \%$, history of treatment with BPA and PEA. Enrolled patients' data including demographics, medication, NT-pro BNP, hemodynamics, PFT and CPET were collected. Ethical approval by the medical ethics committee of Shanghai Pulmonary Hospital was obtained.

\section{CPET}

CPET was performed on an electromagnetically braked cycle ergometer (Master Screen CPX, Jaeger crop,
Hoechberg, Germany) to record gas exchange data over 10 -s intervals by using a breath-by-breath system. The protocol was consisted of the rest phase of $3 \mathrm{~min}$, the unloaded phase of $3 \mathrm{~min}$, the incremental phase, and the recovery phase of $5 \mathrm{~min}$. The patients were instructed to pedal at 55-60 revolutions/min in the unloaded and the incremental phase, and once they reached their limit, entered the recovery phase. Patients could quit at any time if they developed fatigue, dyspnea, chest tightness or any other discomfort during the process. There were three ramp increments models that we used in the incremental phase: $10 \mathrm{~W} / \mathrm{min}, 15 \mathrm{~W} / \mathrm{min}$ and $20 \mathrm{~W} / \mathrm{min}$. We would choose an appropriate model according to the patient's clinical condition and PFT result. Each subject's exercise time includes the unloaded phase of $3 \mathrm{~min}$ and the incremental phase. Some basic information in our research is as follows. In "Mild" group, 8 subjects used $15 \mathrm{~W} / \mathrm{min}$ ramp increments model, and 2 subjects used $20 \mathrm{~W} / \mathrm{min}$ ramp increments model. In "Moderate" group, all 10 subjects used $15 \mathrm{~W} / \mathrm{min}$ ramp increments model. In "Severe" group, 1 subject used $10 \mathrm{~W} /$ min ramp increments model, 29 subjects used $15 \mathrm{~W} / \mathrm{min}$ ramp increments model and 5 subjects used $20 \mathrm{~W} / \mathrm{min}$ ramp increments model. Each group's exercise time is as follows: "Mild" group ( $8.6 \pm 1.4 \mathrm{~min})$, "Moderate" group $(7.6 \pm 1.2 \mathrm{~min})$ and "Severe" group (6.9 $\pm 1.3 \mathrm{~min})$.

Measurements including load, minute ventilation (VE), carbon dioxide output $\left(\mathrm{VCO}_{2}\right)$, oxygen uptake $\left(\mathrm{VO}_{2}\right)$, oxygen pulse $\left(\mathrm{VO}_{2} / \mathrm{HR}\right)$, end-tidal partial pressure for carbon dioxide $\left(\mathrm{PETCO}_{2}\right)$, end-tidal partial pressure for oxygen $\left(\mathrm{PETO}_{2}\right)$, heart rate (HR), breathing reserve (BR), respiratory exchange ratio (RER) and breathing frequency (BF) were recorded and calculated. Anaerobic threshold (AT) which represents the beginning of anaerobic metabolism was determined by the V-slope method and was independently defined by two experienced investigators who have been engaged in clinical and scientific research on CPET for several years. VE/ $\mathrm{VCO}_{2}$ slope was obtained by linear regression analysis of the relation between $\mathrm{VE}$ and $\mathrm{VCO}_{2}$. Oxygen uptake efficiency slope (OUES) was computed by linear square regression from the oxygen uptake on the logarithm of the minute ventilation according to the following equation: $\mathrm{VO}_{2}=\mathrm{a}$ "lgVE $+\mathrm{b}$. Constant "a" is called the OUES. Oxygen uptake efficiency plateau (OUEP) was at $90 \mathrm{~s}$ of the highest consecutive values for $\mathrm{VO}_{2}(\mathrm{~mL} / \mathrm{min}) / \mathrm{VE}(\mathrm{L} /$ $\min$ ).

\section{PFT}

Spirometry and body plethysmography were performed on each patient using standard equipment (Masterscreen-PFT, Jaeger crop, Hoechberg, Germany; Masterscreen-plethysmography, Jaeger crop, Hoechberg, 
Germany). Forced vital capacity (FVC), forced expiratory volume in $1 \mathrm{~s}$ (FEV1), residual volume (RV), total lung capacity (TLC) and diffusing capacity for carbon monoxide (DLCO) were determined by standard procedures $[12,13]$. For each patient, data were presented in absolute terms and normalized to percentage of normal predicted (\% Pred). All measurements were calculated using accepted equations for Chinese adults [14].

\section{Statistical analysis}

Data were analyzed by using SPSS 22.0 and GraphPad Prism 6. The data were presented as mean \pm SD, median (interquartile range), or n. One-way ANOVA test, Kruskal-Wallis test, Unpaired t test, Mann-Whitney U test, chi-square test, univariate logistic regression analysis and multivariate logistic regression analysis were used according to the corresponding situation. A two-tailed $P<0.05$ was considered statistically significant.

\section{Results}

\section{Characteristics of the CTEPH subjects}

55 patients with CTEPH were involved in the test set. They were divided into "Mild", "Moderate" and "Severe" group according to PAP ( $\mathrm{mm} \mathrm{Hg}$ ). Mild: $35>$ PAP (mm $\mathrm{Hg}) \geq 25$; Moderate: $45>$ PAP $(\mathrm{mm} \mathrm{Hg}) \geq 35$; Severe: PAP $(\mathrm{mm} \mathrm{Hg}) \geq 45$.

The characteristics of all groups were summarized in Table 1. The "Severe" group had the highest value of NTproBNP $(\mathrm{pg} / \mathrm{mL})(1082(642.0,2674))$ when compared with the "Mild" (143.0 (63.8, 286.7)) and "Moderate" $(648.5(266.3,2049)$ group. The values of PAP $(\mathrm{mm} \mathrm{Hg})$ of the "Mild", "Moderate" and "Severe" groups were statistically different $(28.6 \pm 3.3$ vs. $39.5 \pm 3.9$ vs. $56.4 \pm 8.0 \mathrm{~mm}$ $\mathrm{Hg} ; \mathrm{P}<0.001$ ). Additionally, the values of PVR (wood $\mathrm{u})$ and RAP $(\mathrm{mm} \mathrm{Hg})$ of the three groups were also statistically different. PVR ( $\operatorname{wood} u$ ) values of the "Mild", "Moderate" and "Severe" group were listed $(3.7 \pm 1.3 \mathrm{vs}$. $7.6 \pm 2.4$ vs. $10.9 \pm 3.8$ wood $\mathrm{u} ; P=0.011)$. And RAP (mm $\mathrm{Hg})$ values of the "Mild" $(0.5(0,4.5))$, "Moderate" $(1.0(0$, $1.3))$ and "Severe" $(4.0(2.0,7.0))$ group were also listed.

Phosphodiesterase type 5 (PDE-5) inhibitors, endothelial receptor antagonists (ERAs), prostacyclin analogs and soluble guanylate cyclase (sGC) activators were therapeutic agents used by the CTEPH patients, which included sildenafil, tadalafil, vadenafil, ambrisentan, bosentan, beraprost and iloprost. Details were listed in Table 1.

\section{CPET and PFT performance differences in subjects with CTEPH}

FEV1/FVC (\%) was the only parameter that was statistically different between the "Severe", "Mild" and "Moderate" group ( $78.8 \pm 9.3$ vs. $81.7 \pm 8.0$ vs. $73.4 \pm 8.0 \%$; $P=0.041$ ). Details were listed in Table 1 .
16 parameters were found to be statistically different among the "Mild", "Moderate" and "Severe" group. They were listed as followed: Load @ Peak (W), $\mathrm{VO}_{2} @$ Rest (mL/kg/min), VO 2 @ Peak (mL/kg/min), VE @ AT (L/min), BR @ Rest (\%), BR @ AT (\%), VE/ $/ \mathrm{VCO}_{2} @ \mathrm{AT}$, $\mathrm{VE} / \mathrm{VCO}_{2} @$ Peak, VE/VO $@$ AT, $\mathrm{PETCO}_{2} @$ Rest (mm $\mathrm{Hg}), \mathrm{PETCO}_{2} @ \mathrm{AT}(\mathrm{mm} \mathrm{Hg}), \mathrm{PETCO}_{2} @$ Peak (mm $\mathrm{Hg}$ ), $\mathrm{PETO}_{2} @ \mathrm{AT}(\mathrm{mm} \mathrm{Hg}), \mathrm{PETO}_{2} @$ Peak $(\mathrm{mm} \mathrm{Hg})$, $\mathrm{VE} / \mathrm{VCO}_{2}$ slope and LOWEST VE/VCO 2 . Details were listed in Tables 2 and 3.

\section{Predictive value of the CPET and PFT parameters for severe CTEPH}

55 patients with CTEPH in the test set were re-grouped into "Mild-Moderate" and "Severe" group to analyze predictors for severe CTEPH. All the CPET and PFT parameters indicated were analyzed with the univariate analysis for the severe $\mathrm{CTEPH}$, and 20 parameters were found to have a $P<0.05$. They were listed in Additional file 1: Table S1. Considering the sample size, 4 parameters with the minimum $P$ value were fitted into the multivariate analysis, including VE @ AT (L/ min) (OR 1.169, $P=0.004), \mathrm{PETCO}_{2} @ \mathrm{AT}(\mathrm{mm} \mathrm{Hg})$ (OR 0.809, $P=0.005), \mathrm{VO}_{2} @$ peak $(\mathrm{mL} / \mathrm{kg} / \mathrm{min})(\mathrm{OR}$ $0.627, P=0.005)$ and LOWEST VE/ $/ \mathrm{VCO}_{2}$ (OR 1.129, $P=0.006)$. By using multivariate logistic regression analysis, it was found that VE @ AT (L/min) (OR 1.162, $P=0.024)$ and $\mathrm{VO}_{2} @$ peak $(\mathrm{mL} / \mathrm{kg} / \mathrm{min})$ (OR 0.633, $P=0.026)$ were independent predictors for the severe CTEPH. Details were listed in Table 4 and Fig. 1.

Multivariate logistic regression was used to establish a prediction model for predicting severe CTEPH: $\operatorname{Logit}(P)=\log (\mathrm{P} / 1-\mathrm{P})=1.753+0.168 * \mathrm{VE} @ \mathrm{AT}(\mathrm{L} /$ $\min )-0.505 * \mathrm{VO}_{2} @$ peak $(\mathrm{mL} / \mathrm{kg} / \mathrm{min})$. To evaluate the ability of the VE@ AT (L/min), VO 2 @ peak $(\mathrm{mL} / \mathrm{kg} / \mathrm{min})$ and the prediction equation to discriminate severe CTEPH, ROC curves and calibration curves analysis were performed. Details were listed in Table 5 and Fig. 2. It should be noted that the AUC of the prediction equation was better than that for each parameter, indicating that the equation based on two parameters could improve the prediction performance for severe CTEPH.

Additionally, the optimum cut-off value of $\operatorname{Logit}(P) \geq 0.716$ to predict severe CTEPH was determined by using ROC analysis (AUC $=0.843,95 \%$ $\mathrm{CI}=0.732$ to 0.954 , Youden index $=0.586$ ). We calculated the value of $\operatorname{Logit}(P)$ of each subject in the validation datasets to validate the results. Only 4 of 31 patients with CTEPH of the validation set were ambiguous, and the accuracy was $87.10 \%$. Details were listed in Table 6. 
Table 1 Characteristics of CTEPH subjects of different severity

\begin{tabular}{|c|c|c|c|c|c|}
\hline Variables & Total & Mild & Moderate & Severe & $P$ \\
\hline \multicolumn{6}{|l|}{ Clinical characteristics } \\
\hline Age (years) & $61.2 \pm 11.2$ & $65.5 \pm 9.9$ & $59.8 \pm 9.3$ & $60.4 \pm 12.0$ & 0.418 \\
\hline Sex, n (female/male) & $31 / 24$ & $4 / 6$ & $7 / 3$ & $20 / 15$ & 0.396 \\
\hline Height (m) & $1.6 \pm 0.1$ & $1.7 \pm 0.1$ & $1.6 \pm 0.1$ & $1.6 \pm 0.1$ & 0.527 \\
\hline Weight (kg) & $63.3 \pm 12.9$ & $65.3 \pm 12.0$ & $56.4 \pm 12.1$ & $64.7 \pm 13.1$ & 0.178 \\
\hline Body mass index $\left(\mathrm{kg} / \mathrm{m}^{2}\right)$ & $23.6 \pm 3.2$ & $23.6 \pm 2.9$ & $20.8 \pm 3.3$ & $24.4 \pm 2.9$ & 0.016 \\
\hline WHO classification $\| / I I / / \mathrm{V}, \mathrm{n}$ & 15/39/1 & $6 / 4 / 0$ & $3 / 6 / 1$ & $6 / 29 / 0$ & 0.017 \\
\hline \multicolumn{6}{|l|}{ Blood test } \\
\hline NT-proBNP (pg/mL) & $809.0(296.9,2284.0)$ & $143.0(63.8,286.7)$ & $648.5(266.3,2049.0)$ & $1082.0(642.0,2674.0)$ & 0.001 \\
\hline \multicolumn{6}{|c|}{ Right heart catheterization parameters } \\
\hline PAP $(\mathrm{mm} \mathrm{Hg})$ & $48.3 \pm 13.2$ & $28.6 \pm 3.3$ & $39.5 \pm 3.9$ & $56.4 \pm 8.0$ & $<0.001$ \\
\hline PAWP (mm Hg) & $7.0(4.0,9.0)$ & $8.5(5.5,10.3)$ & $4.0(3.0,9.3)$ & $7.0(4.0,9.0)$ & 0.250 \\
\hline $\mathrm{CO}(\mathrm{L} / \mathrm{min})$ & $5.0 \pm 1.4$ & $5.8 \pm 1.7$ & $4.8 \pm 1.4$ & $4.9 \pm 1.3$ & 0.221 \\
\hline $\mathrm{Cl}\left(\mathrm{L} / \mathrm{min} / \mathrm{m}^{2}\right)$ & $3.0 \pm 0.8$ & $3.3 \pm 0.8$ & $3.0 \pm 0.7$ & $2.9 \pm 0.7$ & 0.283 \\
\hline PVR (wood u) & $9.0 \pm 4.2$ & $3.7 \pm 1.3$ & $7.6 \pm 2.4$ & $10.9 \pm 3.8$ & 0.011 \\
\hline $\operatorname{RAP}(\mathrm{mm} \mathrm{Hg})$ & $3.0(1.0,6.0)$ & $0.5(0,4.5)$ & $1.0(0,1.3)$ & $4.0(2.0,7.0)$ & 0.001 \\
\hline \multicolumn{6}{|c|}{ Pulmonary function testing parameters } \\
\hline $\mathrm{FVC}(\mathrm{L})$ & $2.7 \pm 0.9$ & $2.8 \pm 0.8$ & $2.8 \pm 1.1$ & $2.6 \pm 0.8$ & 0.790 \\
\hline FVC (\% Pred) & $84.4 \pm 15.8$ & $88.8 \pm 15.6$ & $86.3 \pm 24.9$ & $82.6 \pm 12.5$ & 0.508 \\
\hline FEV1 (L) & $2.1 \pm 0.7$ & $2.2 \pm 0.5$ & $2.2 \pm 0.8$ & $2.0 \pm 0.7$ & 0.488 \\
\hline FEV1 (\% Pred) & $79.5 \pm 17.1$ & $85.7 \pm 14.0$ & $87.0 \pm 23.9$ & $75.6 \pm 14.7$ & 0.076 \\
\hline FEV1/FVC (\%) & $75.9 \pm 8.8$ & $78.8 \pm 9.3$ & $81.7 \pm 8.0$ & $73.4 \pm 8.0$ & 0.041 \\
\hline $\mathrm{RV}(\mathrm{L})$ & $2.4 \pm 0.7$ & $2.5 \pm 0.9$ & $2.6 \pm 0.3$ & $2.3 \pm 0.7$ & 0.562 \\
\hline RV (\% Pred) & $126.8 \pm 34.3$ & $122.6 \pm 46.1$ & $134.9 \pm 27.4$ & $125.7 \pm 32.9$ & 0.700 \\
\hline $\operatorname{TLC}(\mathrm{L})$ & $5.1 \pm 1.3$ & $5.3 \pm 1.5$ & $5.4 \pm 1.2$ & $5.0 \pm 1.3$ & 0.629 \\
\hline TLC (\% Pred) & $100.6 \pm 19.0$ & $101.7 \pm 26.0$ & $104.7 \pm 15.4$ & $99.1 \pm 18.0$ & 0.698 \\
\hline $\mathrm{RV} / \mathrm{TLC}(\%)$ & $47.3(41.8,53.8)$ & $48.3(39.0,53.8)$ & $49.0(39.4,61.0)$ & $47.2(42.0,56.1)$ & 0.910 \\
\hline SB DLCO (\% Pred) & $81.8 \pm 19.2$ & $81.4 \pm 25.2$ & $85.0 \pm 28.7$ & $81.0 \pm 14.0$ & 0.843 \\
\hline \multicolumn{6}{|l|}{ Specific medications } \\
\hline PDE-5 inhibitors $(n, \%)$ & $38(69.1 \%)$ & $9(90.0 \%)$ & $5(50.0 \%)$ & $24(68.6 \%)$ & 0.153 \\
\hline ERAs $(n, \%)$ & $33(60.0 \%)$ & 0 & $7(70.0 \%)$ & $26(74.3 \%)$ & 0.000 \\
\hline Prostacyclin analogs $(n, \%)$ & $1(1.8 \%)$ & $1(10.0 \%)$ & 0 & 0 & 0.101 \\
\hline sGC activators & $3(5.5 \%)$ & 0 & 0 & $3(8.6 \%)$ & 0.404 \\
\hline Combination $(n, \%)$ & $20(36.4 \%)$ & 0 & $2(20.0 \%)$ & $18(51.4 \%)$ & 0.006 \\
\hline
\end{tabular}

Range for "Mild": $35>$ PAP $(\mathrm{mm} \mathrm{Hg}) \geq 25$; range for "Moderate": $45>$ PAP $(\mathrm{mm} \mathrm{Hg}) \geq 35$; range for "Severe": PAP $(\mathrm{mm} H \mathrm{Hg}) \geq 45$. The data are presented as mean \pm SD, median (interquartile range), or n. Statistical analysis of characteristics of "Mild", "Moderate" and "Severe" was analyzed with One-way ANOVA test, KruskalWallis test or chi-square test, and was presented as " $P$ ". WHO $=$ World Health Organization; BNP = brain natriuretic peptide; PAP = pulmonary artery pressure; $\mathrm{PAWP}=$ pulmonary arterial wedge pressure; $\mathrm{CO}=$ cardiac output $\mathrm{Cl}=$ cardiac index; $\mathrm{PVR}=$ pulmonary vascular resistance; $\mathrm{RAP}=$ right atrial pressure; $\mathrm{FVC}=$ forced vital capacity; FEV1 = forced expiratory volume in $1 \mathrm{~s} ; \mathrm{RV}=$ residual volume; TLC=total lung capacity; SB DLCO = carbon monoxide diffusing capacity; PDE-5 inhibitors $=$ phosphodiesterase type 5 inhibitors; ERAs = endothelial receptor antagonists; $\mathrm{sGC}$ activators = soluble guanylate cyclase activators

\section{Discussion}

We retrospectively analyzed the clinical, hematological, PFT and CPET data of 86 patients with CTEPH. Part of the patients were randomly classified into the validation set (a total of 31), and the remaining 55 patients were classified into the test set. Patients with CTEPH in the test set were divided into "Mild", "Moderate" and "Severe" group according to PAP ( $\mathrm{mm} \mathrm{Hg}$ ) detected by RHC to find the parameters that can predict severe CTEPH $[15$,
16]. Results exhibited that there were statistical differences in the CPET performance of patients with different severity of CTEPH. For example, the parameters related with the subjects' exercise capacity were statistically different: Load @ Peak (W), $\mathrm{VO}_{2} @$ Rest $(\mathrm{mL} / \mathrm{kg} / \mathrm{min})$ and $\mathrm{VO}_{2} @$ Peak ( $\left.\mathrm{mL} / \mathrm{kg} / \mathrm{min}\right)$. Several parameters associated with subjects' ventilatory and gas exchange efficiency were also statistically different, including VE @ AT (L/ min), BR @ Rest (\%), BR @ AT (\%), VE/VCO 2 @ AT, VE/ 


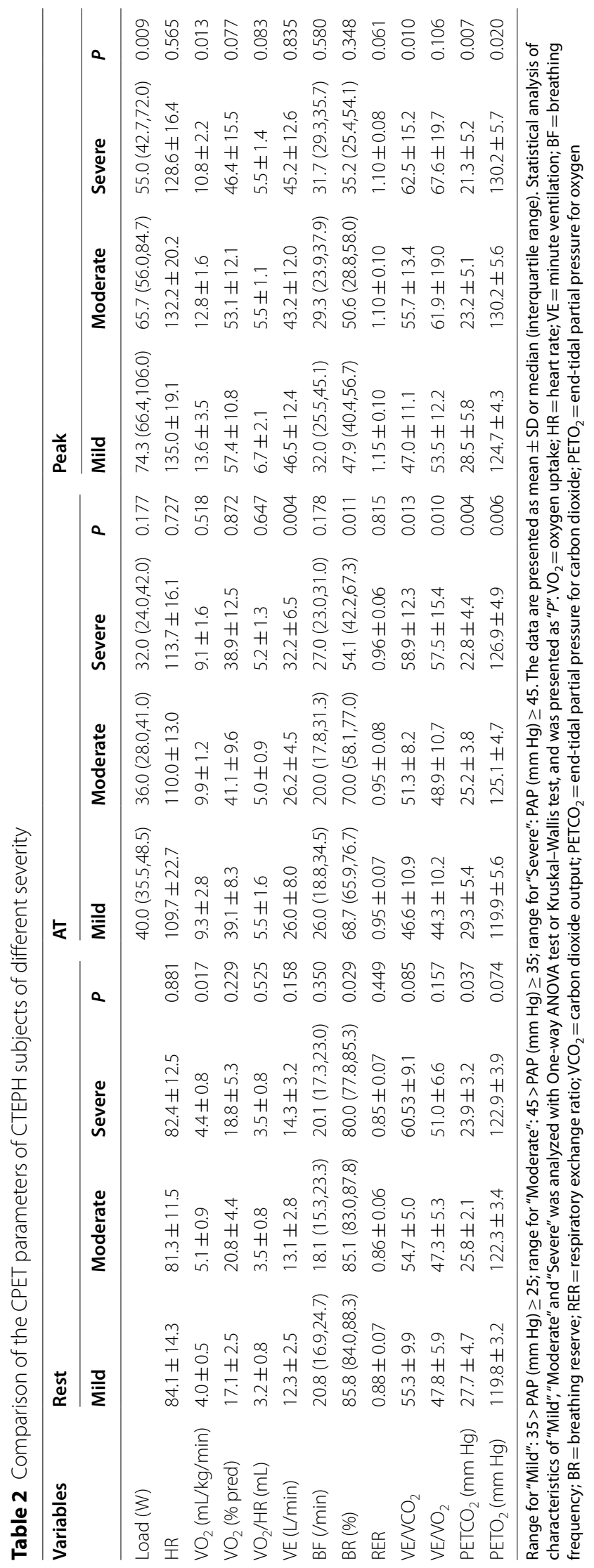


Table 3 Comparison of the CPET parameters of CTEPH subjects of different severity

\begin{tabular}{lllll}
\hline Variables & Mild & Moderate & Severe & $P$ \\
\hline OUES $(\mathrm{L} / \mathrm{min} / \log (\mathrm{L} / \mathrm{min}))$ & $1.3 \pm 0.4$ & $1.0 \pm 0.3$ & $1.0 \pm 0.4$ & 0.066 \\
OUEP $(\mathrm{mL} / \mathrm{L})$ & $23.4(21.0,27.9)$ & $22.7(21.4,23.8)$ & $21.3(19.1,22.7)$ & 0.077 \\
VENCO $_{2}$ slope & $40.9(32.3,53.0)$ & $48.4(41.1,68.7)$ & $61.7(49.9,78.5)$ & 0.005 \\
LOWEST VENCO $_{2}$ & $43.7 \pm 9.1$ & $48.6 \pm 5.8$ & $55.0 \pm 10.1$ & 0.008 \\
\hline
\end{tabular}

Range for "Mild": $35>$ PAP ( $\mathrm{mm} \mathrm{Hg}) \geq 25$; range for "Moderate": $45>$ PAP ( $\mathrm{mm} \mathrm{Hg}) \geq 35$; range for "Severe": PAP (mm Hg) $\geq 45$. The data are presented as mean \pm SD or median (interquartile range). Statistical analysis of characteristics of "Mild", "Moderate" and "Severe" was analyzed with One-way ANOVA test or Kruskal-Wallis test, and was presented as " $P$ ". OUES = oxygen uptake efficiency slope; OUEP = oxygen uptake efficiency plateau; $\mathrm{VE}=$ ventilation; $\mathrm{VCO}{ }_{2}=\mathrm{carbon}$ dioxide output

Table 4 Predictors of severe CTEPH on univariable and multivariable analysis of CPET and PFT parameters

\begin{tabular}{|c|c|c|c|c|c|c|}
\hline \multirow[t]{2}{*}{ Variables } & \multicolumn{3}{|c|}{ Univariate analysis } & \multicolumn{3}{|c|}{ Multivariate analysis } \\
\hline & OR & $P$ & $95 \% \mathrm{Cl}$ & OR & $P$ & $95 \% \mathrm{Cl}$ \\
\hline VE @ AT (L/min) & 1.169 & 0.004 & $1.051-1.300$ & 1.162 & 0.024 & $1.020-1.323$ \\
\hline 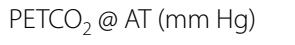 & 0.809 & 0.005 & $0.698-0.938$ & 1.023 & 0.901 & $0.713-1.469$ \\
\hline $\mathrm{VO}_{2} @$ peak $(\mathrm{mL} / \mathrm{kg} / \mathrm{min})$ & 0.627 & 0.005 & $0.452-0.870$ & 0.633 & 0.026 & $0.423-0.948$ \\
\hline LOWEST VE $/ \mathrm{NCO}_{2}$ & 1.129 & 0.006 & $1.036-1.230$ & 1.048 & 0.645 & $0.859-1.279$ \\
\hline
\end{tabular}

Range for "Severe": PAP $(\mathrm{mm} \mathrm{Hg}) \geq 45$. CPET and PFT parameters were all analyzed with univariate logistic regression analysis, and 4 parameters with minimum $P$ value entered in the multivariate logistic regression analysis. Results are expressed as odds ratio (OR) with $95 \%$ confidence interval $(95 \% \mathrm{Cl})$. VE $=$ minute ventilation; $\mathrm{VO}_{2}=$ oxygen uptake; $\mathrm{VCO}_{2}=$ carbon dioxide output; $\mathrm{PETCO}_{2}=$ end-tidal partial pressure for carbon dioxide

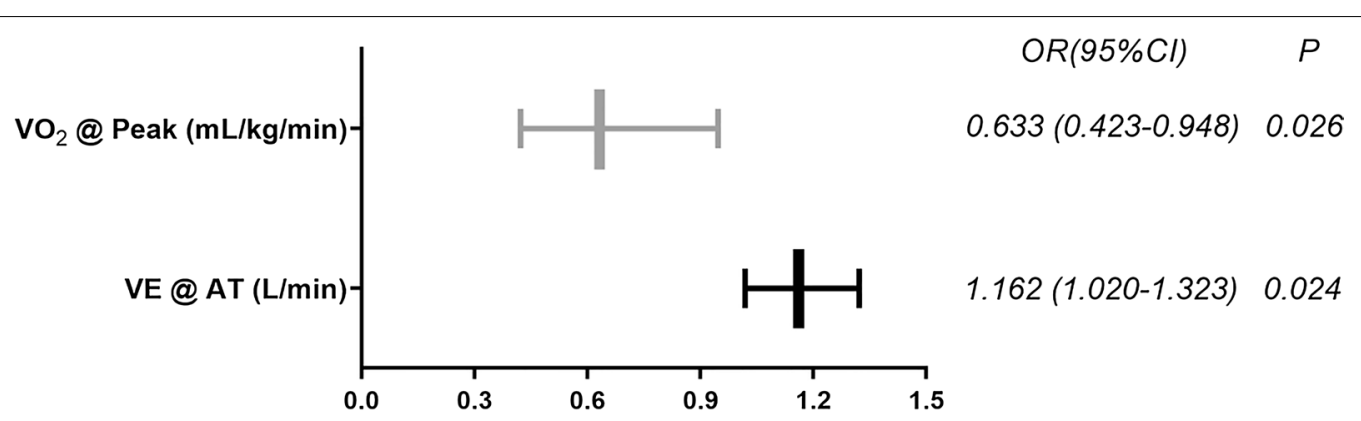

Fig. 1 Predictors of severe CTEPH on multivariable analysis of CPET and PFT parameters. Range for "Severe": PAP (mm Hg) $\geq 45$. Results are expressed as odds ratio (OR) with $95 \%$ confidence interval $(95 \% \mathrm{Cl})$. $\mathrm{VE}=$ minute ventilation; $\mathrm{VO}_{2}=$ oxygen uptake

Table 5 Predictive value of single factor and multiple factors for severe CTEPH

\begin{tabular}{llllllll}
\hline Variables & AUC & $\mathbf{9 5 \%} \mathrm{Cl}$ & $\boldsymbol{P}$ & $\begin{array}{l}\text { Cutoff-point } \\
\text { value }\end{array}$ & Sensitivity & Specificity & Youden index \\
\hline VE @ AT (L/min) & 0.769 & $0.630-0.908$ & 0.001 & 29.5 & $65.7 \%$ & $85.0 \%$ & 0.507 \\
$\mathrm{VO}_{2} @$ Peak $(\mathrm{mL} / \mathrm{kg} / \mathrm{min})$ & 0.740 & $0.606-0.874$ & 0.003 & 13.0 & $50.0 \%$ & $91.4 \%$ & 0.414 \\
Logit $(P)$ & 0.843 & $0.732-0.954$ & 0.000 & 0.716 & $68.6 \%$ & $90.0 \%$ & 0.586 \\
\hline
\end{tabular}

Range for "Severe": PAP $(\mathrm{mm} \mathrm{Hg}) \geq 45$. AUC = area under ROC curve; $\mathrm{Cl}=$ confidence interval; $\mathrm{VE}=$ minute ventilation; $\mathrm{VO}_{2}=$ oxygen uptake

$\mathrm{VCO}_{2} @$ Peak, VE/VO $\mathrm{VO}_{2} @ \mathrm{AT}, \mathrm{PETCO}_{2} @ \mathrm{Rest}(\mathrm{mm} \mathrm{Hg})$, $\mathrm{PETCO}_{2} @ \mathrm{AT}(\mathrm{mm} \mathrm{Hg}), \mathrm{PETCO}_{2} @$ Peak $(\mathrm{mm} \mathrm{Hg})$, $\mathrm{PETO}_{2} @ \mathrm{AT}(\mathrm{mm} \mathrm{Hg}), \mathrm{PETO}_{2} @$ Peak (mm Hg), VE/ $\mathrm{VCO}_{2}$ slope and LOWEST VE/VCO ${ }_{2}$.
The patients with CTEPH in the test set were regrouped into "Mild-Moderate" and "Severe" group to analyze predictors for severe CTEPH by univariate and multivariate analysis. The results indicated that VE @ AT (L/min) and $\mathrm{VO}_{2} @$ Peak $(\mathrm{mL} / \mathrm{kg} / \mathrm{min})$ were independent predictors 


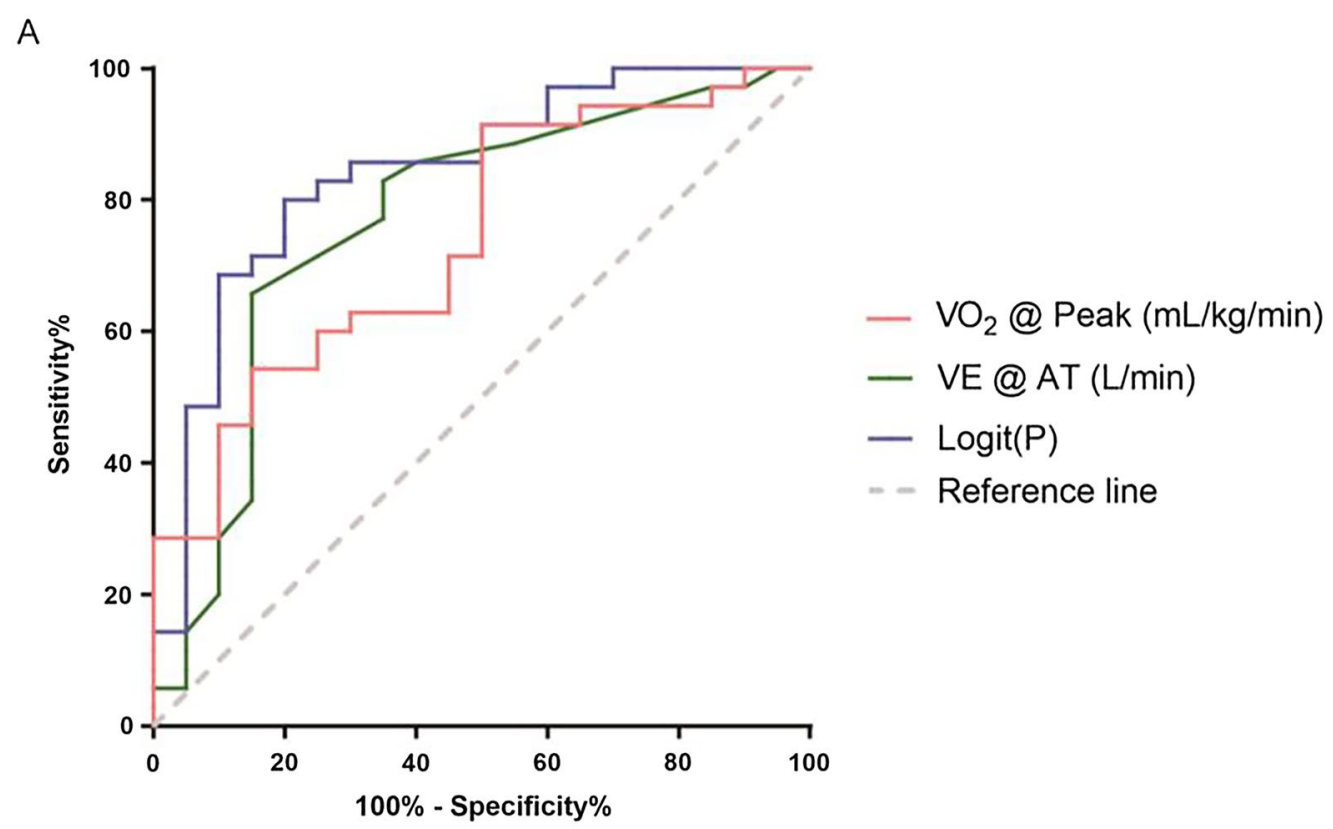

B

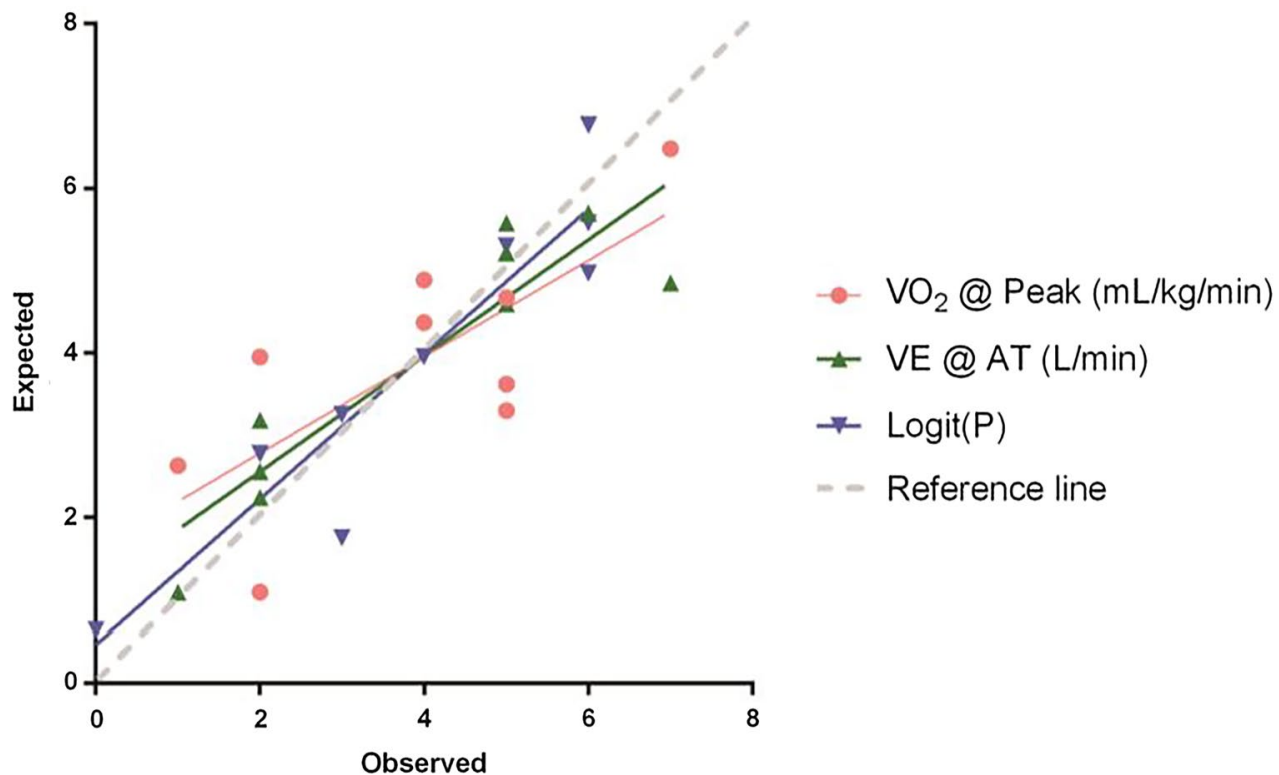

Fig. 2 Performance of CPET parameters for the prediction of severe CTEPH. A Receiver operating characteristic (ROC) curves for single factor and multiple factors that predict severe CTEPH. B Calibration curves for single factor and multiple factors that predict severe CTEPH

for severe CTEPH. Combining these two parameters, we got a prediction equation for severe CTEPH. ROC curves and calibration curves proved that the prediction equation was good in discrimination and calibration. Additionally, the prediction equation's application in the validation set further confirmed its efficiency.

CTEPH which is kind of pulmonary vascular disease is associated with hypoperfusion of the ventilated alveoli, and it leads to the alveoli with non-occluded capillaries must be ventilated to a proportionately greater degree than normal to remove $\mathrm{CO}_{2}$ and to maintain $\mathrm{PaCO}_{2}, \mathrm{PaO}_{2}$ at appropriate levels [17]. Due to increased physiological dead space and low- $\mathrm{PaO}_{2}$ driven ventilation, increased ventilation was observed in patients with CTEPH. The increase in VE was observed in patients with CTEPH at rest phase and to a greater degree during exercise phase. 
Table 6 Characteristics of subjects with Logit $(P)<0.716$ and Logit $(P)>0.716$ calculated by the predication equation in validation set

\begin{tabular}{lllr}
\hline Variables & Logit $(\boldsymbol{P})<\mathbf{0 . 7 1 6}$ & Logit $(\boldsymbol{P})>\mathbf{0 . 7 1 6}$ & $\boldsymbol{P}$ \\
\hline Age (years) & $54.0 \pm 13.0$ & $60.8 \pm 6.7$ & 0.102 \\
Sex, $\mathrm{n}(\mathrm{female} / \mathrm{male})$ & $14 / 5$ & $7 / 5$ & 0.075 \\
Height $(\mathrm{m})$ & $1.6 \pm 0.1$ & $1.6 \pm 0.1$ & 0.348 \\
Weight $(\mathrm{kg})$ & $61.2 \pm 10.2$ & $66.4 \pm 10.9$ & 0.187 \\
Body mass index $\left(\mathrm{kg} / \mathrm{m}^{2}\right)$ & $23.7 \pm 3.8$ & $24.5 \pm 2.6$ & 0.501 \\
WHO classification IIIIII/IV, & $10 / 9 / 0$ & $2 / 9 / 1$ & 0.082 \\
NT-proBNP $(\mathrm{pg} / \mathrm{mL})$ & $203.0(79.0,634.0)$ & $1305.0(659.0,2284.0)$ & 0.002 \\
PAP $(\mathrm{mm} \mathrm{Hg})$ & $36.3 \pm 11.7$ & $53.0 \pm 4.6$ & $<0.0001$ \\
PAWP $(\mathrm{mm} \mathrm{Hg})$ & $7.5 \pm 3.7$ & $6.3 \pm 2.6$ & 0.338 \\
CO $(\mathrm{L} / \mathrm{min})$ & $4.9 \pm 1.0$ & $4.2 \pm 1.0$ & 0.075 \\
Cl $\left(\mathrm{L} / \mathrm{min} / \mathrm{m}^{2}\right)$ & $3.0 \pm 0.5$ & $2.5 \pm 0.5$ & 0.017 \\
PVR $($ wood u) & $6.3 \pm 2.6$ & $11.5 \pm 3.6$ & $<0.0001$ \\
RAP $(\mathrm{mm} \mathrm{Hg})$ & $3.0(2.0,5.0)$ & $7.5(3.5,8.8)$ & 0.045 \\
VE @ AT $(\mathrm{L} / \mathrm{min})$ & $26.0 \pm 6.4$ & $35.6 \pm 7.1$ & 0.001 \\
VO ${ }_{2} @$ Peak $(\mathrm{mL} / \mathrm{kg} / \mathrm{min})$ & $13.8 \pm 2.7$ & $11.1 \pm 1.8$ & 0.005 \\
\hline
\end{tabular}

The data are presented as mean \pm SD, median (interquartile range), or $n$. Statistical analysis of characteristics of "Logit $(P)<0.716^{\prime \prime}$ and "Logit $(P)>0.716^{\prime \prime}$ was analyzed with Unpaired $t$ test, Mann-Whitney $\mathrm{U}$ test or chi-square test, and was presented as " $P$ ". WHO =World Health Organization; BNP = brain natriuretic peptide; $\mathrm{PAP}=$ pulmonary artery pressure; $\mathrm{PAWP}=$ pulmonary arterial wedge pressure; $\mathrm{CO}=$ cardiac output $\mathrm{Cl}=$ cardiac index; $\mathrm{PVR}=$ pulmonary vascular resistance; $\mathrm{RAP}=$ right atrial pressure; $\mathrm{VE}=$ minute ventilation; $\mathrm{VO}_{2}=$ oxygen uptake

Compared with pulmonary arterial hypertension (PAH) patients, CTEPH patients have higher VE values and lower BR (\%) values at AT phase [18]. In our study, it was also observed that VE values at AT phase were closely related with the severity of CTEPH. During exercise, AT is termed as the level of $\mathrm{VO}_{2}$ above which aerobic energy production is supplemented by anaerobic mechanisms, lactate continuously increases and metabolic acidosis occurs. Above the AT, VE increases disproportionately to the metabolic requirement to emit $\mathrm{CO}_{2}$ to alleviate metabolic acidosis. This may explain to a certain extent, the VE @ AT can more accurately reflect the pathological ventilation of patients with CTEPH than VE @ Peak [19].

CPET can be used for the diagnosis/differential diagnosis, prognostic evaluation and treatment evaluation of CTEPH. Compared with healthy subjects, patients with CTEPH had higher values of $\mathrm{VE} / \mathrm{VO}_{2} @ \mathrm{AT}, \mathrm{VE} / \mathrm{VCO}_{2}$ @ AT, $\mathrm{P}(\mathrm{c}-\mathrm{ET}) \mathrm{CO}_{2}$ while had lower values of $\mathrm{PETCO}_{2} @$ AT. Among these parameters, $\mathrm{P}(\mathrm{c}-\mathrm{ET}) \mathrm{CO}_{2}$ was a diagnostic parameter of CTEPH with the highest sensitivity (85.7\%) and specificity (88.2\%) [20]. Ventilatory efficiency parameters including $\mathrm{P}(\mathrm{c}-\mathrm{ET}) \mathrm{CO}_{2}$, VD/VT @ Peak, VE/ $\mathrm{VCO}_{2}$ slope, VE/VCO $/ \mathrm{VO}_{2} @ \mathrm{AT}, \mathrm{OUEP}$ and OUE @ AT can help to distinguish CTEPH from idiopathic pulmonary arterial hypertension (IPAH) [18, 21-23]. The lowest VE/ VCO2 ratio could be used to predict CTEPH in patients with chronic PE [24]. Godinas et al. reported that in distal CTEPH patients, higher values of VD/VT were associated with worse survival [25]. Jin et al. reported that after BPA, patients with inoperable CTEPH had better CPET and PFT performance, including improvements in Load @ Peak, VO 2 @ Peak, OUES, FVC, FEV1 and MVV [26].

For the first time, we have evaluated the CPET performance in CTEPH patients of different severity. For patients who have already been diagnosed with mild CTEPH by the RHC, it's necessary to continuously monitor the disease progression. However, patients' clinical signs and symptoms can be nonspecific [27]. Unlike the invasive method RHC, CPET is a non-invasive tool that can help to identify patients with milder abnormalities. We hope that CPET can be used for routine monitoring of CTEPH patients in the future, and then the application of these parameters and this formula can provide value for guiding patients' the further examination and treatment.

As a similar non-invasive test, echocardiography makes it possible to estimate the systolic PAP based on the measured tricuspid regurgitation velocity (TRV) at rest and on the presence of additional echocardiographic variables that suggest $\mathrm{PH}$. Although echocardiography is undoubtedly the most important non-invasive test for grading the probability of $\mathrm{PH}$, it also has its limitations: only $90 \%$ of $\mathrm{PH}$ patients have TRV [28]. In symptomatic patients with a clinical suspicion of $\mathrm{PH}$, the diagnosis of $\mathrm{PH}$ is missed by echocardiography in $10-30 \%$ of cases, even if indirect signs are taken into consideration $[29,30]$. Recently, there was a report that CPET could serve as complementary tool in the diagnosis of CTEPH and can detect CTEPH in patients with normal echocardiography [20]. In the 
future, perhaps the combination of the two methods will bring the greatest benefits to patients.

In general, our study shows that VE @ AT (L/min) and $\mathrm{VO}_{2} @$ Peak $(\mathrm{mL} / \mathrm{kg} / \mathrm{min})$ were statistically significant independent predictors for severe CTEPH. The prediction equation $\operatorname{Logit}(P)=1.753+0.168 * \mathrm{VE} @ \mathrm{AT}$ $(\mathrm{L} / \mathrm{min})-0.505 * \mathrm{VO}_{2}$ @ peak $(\mathrm{mL} / \mathrm{kg} / \mathrm{min})$ was effective and efficient in discriminating patients with severe CTEPH. There are some methodological limitations. Since most patients are undergoing CPET for the first time, we know very little about their cardiopulmonary function and exercise ability. We just chose a ramp increments model that may be the best based on their clinical condition and PFT result. From the perspective of exercise time, a lower ramp increments model may be more preferable. In the future, if CPET is listed as a regular routine monitoring of patients, so as to establish a file for the patient, this trouble may be avoided. Some of other limitations of this study are its patient sample size, non-randomized nature, single-center design and potential selection bias. Since it's a retrospective study, it is a bit difficult for us to continuously monitor the CTEPH patient's disease progression and corresponding CPET and PFT performance. However, we will further verify these research conclusions in the following prospective studies on CTEPH patient's CPET and PFT performance.

\section{Conclusions}

Our research suggests that CPET and PFT can noninvasively and effectively evaluate, monitor and predict the severity of CTEPH. VE @ AT (L/min) and $\mathrm{VO}_{2} @$ Peak $(\mathrm{mL} / \mathrm{kg} / \mathrm{min})$ were statistically significant independent predictors for severe CTEPH.

\footnotetext{
Abbreviations

CPET: Cardiopulmonary exercise testing; PFT: Pulmonary function testing; CTEPH: Chronic thromboembolic pulmonary hypertension; PH: Pulmonary hypertension; PPH: Primary pulmonary hypertension; IPAH: Idiopathic pulmonary arterial hypertension; HF: Heart failure; COPD: Chronic obstructive lung disease; PE: Pulmonary embolism; PEA: Pulmonary endarterectomy; BPA: Balloon pulmonary angioplasty; RHC: Right heart catheterization; CTPA: CT pulmonary angiography; V/Q: Ventilation/perfusion scan; ROC: Receiver operating characteristic curves; AUC: Area under the ROC curve; OR: Odds ratio; Cl: Confidence interval; WHO: World Health Organization; BNP: Brain natriuretic peptide; PAP: Pulmonary artery pressure; PAWP: Pulmonary arterial wedge pressure; CO: Cardiac output; Cl: Cardiac index; PVR: Pulmonary vascular resistance; RAP: Right atrial pressure; FVC: Forced vital capacity; FEV1: Forced expiratory volume in $1 \mathrm{~s}$; RV: Residual volume; TLC: Total lung capacity; SB DLCO: Carbon monoxide diffusing capacity; $\mathrm{VO}_{2}$ : Oxygen uptake; HR: Heart rate; VE: Minute ventilation; $\mathrm{BF}$ : Breathing frequency; $\mathrm{BR}$ : Breathing reserve; RER: Respiratory exchange ratio; $\mathrm{VCO}_{2}$ : Carbon dioxide output; VD/NT: Dead space ventilation as a fraction of tidal volume; PETCO $_{2}$ : End-tidal partial pressure for carbon dioxide; $\mathrm{PETO}_{2}$ : End-tidal partial pressure for oxygen; OUES: Oxygen uptake efficiency slope; OUEP: Oxygen uptake efficiency plateau; VE: Ventilation; $\mathrm{VCO}_{2}$ : Carbon dioxide output; AT: Anaerobic threshold.
}

\section{Supplementary Information}

The online version contains supplementary material available at https://doi. org/10.1186/s12890-021-01668-3.

Additional file 1. Supplementary Table 1. Predictors of severe CTEPH on univariable analysis of CPET and PFT parameters.

\section{Acknowledgements}

Not applicable.

\section{Authors' contributions}

Conceived and designed the experiments: ZH LJ GJ. Performed the experiments: SX CY YW. Analyzed the data: ZH GJ. Contributed reagents/materials/analysis tools: ZH SX. Wrote the paper: ZH SX GJ. All authors read and approved the final manuscript.

\section{Funding}

This study was supported by the Scientific research project of Shanghai Municipal Health Commission [202040321], the Clinical research project of Shanghai Pulmonary Hospital [FKLY20020] and cultivation project of Shanghai Pulmonary Hospital [fkzr2032].

\section{Availability of data and materials}

All the related data are presented in the manuscript.

\section{Declarations}

\section{Ethics approval and consent to participate}

All patients in this study were informed at admission that their medical records were likely to be used for clinical studies. Ethical approval by the medical ethics committee of Shanghai pulmonary hospital was obtained.

\section{Consent for publication}

Not applicable.

\section{Competing interests}

The authors confirm that there are no conflicts of interest.

\section{Author details}

${ }^{1}$ Department of Pulmonary Function Test, Shanghai Pulmonary Hospital, School of Medicine, Tongji University, Shanghai 200092, China. ${ }^{2}$ Department of Internal Medicine, Columbia Bainuo Clinic, Shanghai 200040, China.

Received: 10 May 2021 Accepted: 10 September 2021

Published online: 18 October 2021

\section{References}

1. Guazzi M, Bandera F, Ozemek C, Systrom D, Arena R. Cardiopulmonary exercise testing: what is its value? J Am Coll Cardiol. 2017;70:1618-36.

2. Tran D. Cardiopulmonary exercise testing. Methods in molecular biology (Clifton, NJ). 2018;1735:285-95.

3. Weatherald J, Farina S, Bruno N, Laveneziana P. Cardiopulmonary exercise testing in pulmonary hypertension. Ann Am Thorac Soc. 2017;14:S84-92.

4. Malhotra R, Bakken K, D'Elia E, Lewis GD. Cardiopulmonary exercise testing in heart failure. JACC Heart failure. 2016;4:607-16.

5. Boutou AK, Daniil Z, Pitsiou G, Papakosta D, Kioumis I, Stanopoulos I. Cardiopulmonary exercise testing in patients with asthma: What is its clinical value? Respir Med. 2020;167:105953.

6. Simonneau G, Torbicki A, Dorfmüller P, Kim N. The pathophysiology of chronic thromboembolic pulmonary hypertension. Eur Respir Rev. 2017;26:160112.

7. Coons JC, Pogue K, Kolodziej AR, Hirsch GA, George MP. Pulmonary arterial hypertension: a pharmacotherapeutic update. Curr Cardiol Rep. 2019;21:141. 
8. Kharat A, Hachulla AL, Noble S, Lador F. Modern diagnosis of chronic thromboembolic pulmonary hypertension. Thromb Res. 2018;163:260-5.

9. Paolillo S, Farina S, Bussotti M, lorio A, PerroneFilardi P, Piepolil MF, et al. Exercise testing in the clinical management of patients affected by pulmonary arterial hypertension. Eur J Prev Cardiol. 2012;19:960-71.

10. Sun XG, Hansen JE, Oudiz RJ, Wasserman K. Exercise pathophysiology in patients with primary pulmonary hypertension. Circulation. 2001;104:429-35.

11. Yasunobu Y, Oudiz RJ, Sun XG, Hansen JE, Wasserman K. End-tidal PCO2 abnormality and exercise limitation in patients with primary pulmonary hypertension. Chest. 2005;127:1637-46.

12. Cotes JE, Chinn DJ, Quanjer PH, Roca J, Yernault JC. Standardization of the measurement of transfer factor (diffusing capacity). Eur Respir J. 1993;6(Suppl 16):41-52.

13. Stocks J, Quanjer PH. Reference values for residual volume, functional residual capacity and total lung capacity. ATS Workshop on Lung Volume Measurements. Official Statement of The European Respiratory Society. The European respiratory journal. 1995; 8: 492-506.

14. Mu KLS. Summary of Chinese pulmonary function normal values. Beijing: Beijing Medical University and Peking Union Medical College Press; 1990. p. 83-6.

15. Olsson KM, Channick R. Pregnancy in pulmonary arterial hypertension. Eur Respir Rev. 2016;25:431-7.

16. Mangus RS, Kinsella SB, Marshall GR, Fridell JA, Wilkes KR, Tector AJ. Mild to moderate pulmonary hypertension in liver transplantation. J Surg Res. 2013;184:1150-6.

17. Kikuchi H, Goda A, Takeuchi K, Inami T, Kohno T, Sakata K, et al. Exercise intolerance in chronic thromboembolic pulmonary hypertension after pulmonary angioplasty. Eur Respir J. 2020;56:1901982.

18. Zhai Z, Murphy K, Tighe H, Wang C, Wilkins MR, Gibbs JSR, et al. Differences in ventilatory inefficiency between pulmonary arterial hypertension and chronic thromboembolic pulmonary hypertension. Chest. 2011;140:1284-91.

19. Wasserman K. Determinants and detection of anaerobic threshold and consequences of exercise above it. Circulation. 1987;76:VI29-1139.

20. Held M, Grün M, Holl R, Hübner G, Kaiser R, Karl S, et al. Cardiopulmonary exercise testing to detect chronic thromboembolic pulmonary hypertension in patients with normal echocardiography. Respir Int Rev Thoracic Dis. 2014;87:379-87.

21. Scheidl SJ, Englisch C, Kovacs G, Reichenberger F, Schulz R, Breithecker A, et al. Diagnosis of CTEPH versus IPAH using capillary to end-tidal carbon dioxide gradients. Eur Respir J. 2012;39:119-24.
22. Ramos RP, Ferreira EVM, Valois FM, Cepeda A, Messina CMS, Oliveira RK, et al. Clinical usefulness of end-tidal $\mathrm{CO}(2)$ profiles during incremental exercise in patients with chronic thromboembolic pulmonary hypertension. Respir Med. 2016;120:70-7.

23. Shi X, Guo J, Gong S, Sapkota R, Yang W, Liu H, et al. Oxygen uptake is more efficient in idiopathic pulmonary arterial hypertension than in chronic thromboembolic pulmonary hypertension. Respirology (Carlton, Vic). 2016;21:149-56.

24. Xi Q, Zhao Z, Liu Z, Ma X, Luo Q, Liu W. The lowest VENCO, ratio best identifies chronic thromboembolic pulmonary hypertension. Thromb Res. 2014;134:1208-13.

25. Godinas L, Sattler C, Lau EM, Jaïs X, Taniguchi Y, Jevnikar M, et al. Deadspace ventilation is linked to exercise capacity and survival in distal chronic thromboembolic pulmonary hypertension. J Heart Lung Transplant. 2017;36:1234-42.

26. Jin Q, Luo Q, Yang T, Zeng Q, Yu X, Yan L, et al. Improved hemodynamics and cardiopulmonary function in patients with inoperable chronic thromboembolic pulmonary hypertension after balloon pulmonary angioplasty. Respir Res. 2019;20:250.

27. Gopalan D, Delcroix M, Held M. Diagnosis of chronic thromboembolic pulmonary hypertension. Eur Respir Rev. 2017;26:160108.

28. Kovacs G, Dumitrescu D, Barner A, Greiner S, Grünig E, Hager A, et al. Definition, clinical classification and initial diagnosis of pulmonary hypertension: Updated recommendations from the Cologne Consensus Conference 2018. Int J Cardiol. 2018;272S:11-9.

29. Coghlan JG, Denton CP, Grünig E, Bonderman D, Distler O, Khanna D, et al Evidence-based detection of pulmonary arterial hypertension in systemic sclerosis: the DETECT study. Ann Rheum Dis. 2014;73:1340-9.

30. Held M, Grün M, Holl R, Walter F, Schäfers HJ, Graeter T, et al. Chronic thromboembolic pulmonary hypertension: time delay from onset of symtoms to diagnosis and clinical condition at diagnosis. Dtsch Med Wochenschr. 1946;2014(139):1647-52.

\section{Publisher's Note}

Springer Nature remains neutral with regard to jurisdictional claims in published maps and institutional affiliations.
Ready to submit your research? Choose BMC and benefit from:

- fast, convenient online submission

- thorough peer review by experienced researchers in your field

- rapid publication on acceptance

- support for research data, including large and complex data types

- gold Open Access which fosters wider collaboration and increased citations

- maximum visibility for your research: over $100 \mathrm{M}$ website views per year

At BMC, research is always in progress.

Learn more biomedcentral.com/submissions 